\title{
PROCESSOS MORFOLÓGICOS E FONOLÓGICOS NO PORTUGUESS ARCAICO: IMPERATIVO E SÂNDI VOCÁLICO EXTERNO
} Ana Carolina Cangemi*

(D) http://orcid.org/0000-0001-5395-9862

Gisela Fávaro**

(iD) http://orcid.org/0000-0002-7321-7935

Como citar este artigo: CANGEMI, A. C.; FÁVARO, G. Processos morfológicos e fonológicos no português arcaico: imperativo e sândi vocálico externo. Todas as Letras Revista de Lingua e Literatura, São Paulo, v. 22, n. 1, p. 1-14, jan./abr. 2020. DOI 10.5935/1980-6914/eLETDO2012716

Submissão: agosto de 2019. Aceite: fevereiro de 2020.

Resumo: O principal objetivo deste estudo é refletir acerca da importância do uso das Cantigas de Santa Maria (CSM), como corpus para o desenvolvimento de análises linguísticas referente a estudos relacionados à língua portuguesa no período arcaico. Em relação aos fenômenos morfológicos e fonológicos que envolvem acento e ritmo, é preciso considerar um corpus que os ampare. Assim, textos poéticos são pertinentes, pois há escansão, que consiste na contagem dos sons e dos versos a partir da elevação de ritmo ou tonicidade das palavras.

Palavras-chave: Linguística histórica. Morfologia. Fonologia. Português arcaico. Cantigas medievais. 


\section{INTRODUÇÃo}

N este artigo, buscamos demonstrar a importância das Cantigas de Santa Maria (CSM), como corpus, para análise de processos morfológicos e fonológicos em português arcaico (PA). Embora existam outros gêneros textuais ${ }^{1}$ remanescentes do período medieval, assim como Massini-Cagliari (1995), consideramos os poemas medievais galego-portugueses por entender que as descrições de fenômenos morfológicos e fonológicos são mais bem amparados com a consideração de elementos poéticos, como acento, ritmo e metrificação, pertencentes ao gênero.

Primeiramente, apresentamos as CSM, na seção "Corpus". Em seguida, evidenciamos a metodologia utilizada, tecemos considerações sobre os objetos de estudo (para a morfologia, trazemos o modo imperativo e, para a fonologia, o sândi vocálico externo) e, por fim, encerramos com a demonstração de uma análise de dados recolhidos.

\section{CORPUS}

O corpus é constituído pelas CSM. Há vários autores que discorrem sobre a importância das cantigas tanto em um aspecto histórico de produção sacra quanto em um representativo da língua portuguesa. Elencamos sete estudiosos e seus dizeres a respeito das CSM.

Iniciamos com Ferreira (1994). De acordo com o autor, as CSM são "[...] the collection of more than four hundred songs dedicated to the Virgin Mary by Alfonso X, the King of Castile and Léon, survives in four medieval manuscripts" 2 (FERREIRA, 1994, p. 58).

O segundo autor que trazemos a tratar sobre as CSM é Parkinson (1998). Para ele, as CSM constituem um monumento literário, musical e artístico da mais elevada importância e sua escolha como objeto de estudo se dá devido à grande riqueza lexical que apresentam.

O'Callaghan (1998, p. 2) também ressalta a importância das CSM ao afirmar que "[...] the poems were written in the language od medieval Galicia and Portugal, the medium of expression. Preferred by the lyric poets of tha day"3.

Sobre o espaço em que foram produzidas as CSM, Leão (2002, p. 1) afirma que foi em um ambiente de efervescência cultural que nasceram os textos poéticos. De acordo com Parkinson (1998, p. 179), a intenção dessa coletânea sempre foi a de louvar a Virgem e aumentar a devoção a ela. Por esse motivo, todas as cantigas são, na verdade, de louvor e exaltam a Mãe de Deus. Filgueira Valverde $(1985$, p. 49) ressalta que diversos milagres marianos foram recolhidos de igrejas e santuários europeus, sobretudo franceses e ibéricos, e são de fonte con-

1 Além dos poemas trovadorescos e das Cantigas de Santa Maria, existem outros gêneros textuais que também foram preservados ao longo dos anos. Trata-se de arquivos jurídicos, os chamados documentos notariais, que apresentam como temas doações de terras, testamentos, compra ou venda de imóveis, inventários etc. Há também os forais ou costumes, cujo conteúdo reúne leis locais que estabeleciam as normas disciplinares em relação aos habitantes. De acordo com Mattos e Silva (2006, p. 38-39), esses textos são importantes para o conhecimento do português arcaico, pois são significativos e informativos, além de trazerem as datas em que foram exarados. Porém, no que concerne à riqueza ao conhecimento da sintaxe, tais textos não são valiosos, em função de a estrutura formular ser muito restrita, "às vezes alatinada, natural a este tipo de texto que segue modelos da tradição jurídica latina".

2 "[...] coleção com mais de quatrocentas cantigas dedicadas à Virgem Maria, elaboradas por Afonso X, o rei de Castela e Leão, que sobrevivem em quatro manuscritos medievais" (tradução nossa).

3 "[...] os poemas foram escritos na linguagem medieval da Galícia e de Portugal, o meio de expressão preferido dos poetas líricos daqueles tempos" (tradução nossa). 
firmada e bem conhecida, mas muitos relatos ainda hoje são desconhecidos e provavelmente apenas orais.

Ferreira (1994) também afirma que, do ponto de vista musical, as cantigas religiosas são especialmente notáveis entre a documentação remanescente de música medieval. Ainda em relação ao local onde ocorriam as manifestações artísticas e culturais, Pena (1992, p. 23) ressalta que a poesia, estritamente unida à música, era um divertimento no período da Idade Média.

\section{FUNDAMENTAÇÃo TEÓRICA}

\section{Concepção teórica prévia: o morfema}

O conceito de morfema é muito importante quando se trata de análises que abordam aspectos morfológicos. Rocha (1999, p. 27) afirma que, no afã de descrever as linguas, os estruturalistas chegaram ao conceito de morfema. Bloomfield (1984 [1933], p. 564) diz que o morfema é uma forma recorrente (com significado) que não pode ser analisada em formas recorrentes (significativas) menores. Monteiro (2002, p. 13) também possui uma definição para o conceito de morfema. O autor, assim como demais estudiosos, declara que morfema é a menor unidade dotada de significado. De acordo com ele, o morfema é uma unidade abstrata e, na prática, pode representar várias formas. Ao observarmos as palavras vida e vital, parece claro que em ambas as ocorrências há um mesmo morfema, que se realiza como [vid] e [vit].

Ainda sobre a definição de morfemas, é importante ressaltar a existência do processo de cumulação. Para Rosa (2000, p. 65), na análise morfêmica espera-se que a um elemento de significado deva corresponder um elemento no nivel da expressão e vice-versa. Porém, ao propor que um único morfe possa representar a vogal temática e a desinência para TMA (cf. verbo amar conjugado na segunda pessoa do singular: $a m$ - [raiz], $-a-$ [VT+ind.pres] $+-s$ [ $\left.\left.2^{a} \mathrm{ps}\right]\right)$, quebra a afirmação inicial, uma vez que um único morfe representa duas posições distintas do padrão verbal, como pode ser observado em amo $\left(1^{\mathrm{a}}\right.$ pessoa do singular do presente do indicativo).

Outro conceito morfológico relevante para o desenvolvimento desta pesquisa é a distinção entre radical e tema. Rocha (1999, p. 102) define raiz como sendo um morfema comum a várias palavras de um mesmo grupo lexical, portador da significação básica desse grupo de palavras. Para o autor,

[...] em claro, clarear, aclarar, esclarecer, esclarecimento e clarividência, a raiz é clar-. Em livro, livrinho, livreiro, livraria e livresco, a raiz é livr-. Em tom, tonal, tonicidade, entoar, desentoar, toado e desentoadamente, a raiz é tom, com a variante to- (ROCHA, 1999, p. 102).

Os conceitos de morfema, raiz e radical são muito relevantes para o desenvolvimento das análises dos dados, pois, para compreender o funcionamento das formas verbais conjugadas no modo imperativo e verificar se estávamos diante de formas variantes ou não, foi necessário realizar primeiro uma divisão morfológica dos dados.

\section{Concepção teórica prévia: os processos fonológicos}

O conceito de processos fonológicos foi concebido por Stampe (1973). De acordo com o autor, 
[...] a phonological process is a mental operation that applies in speech to substitute, for a class of sound or sound sequences a specific common difficulty to the speech capacity of the individual, an alternative class identical but lacking the difficulty property (STAMPE, 1973, p. 1)

Os processos fonológicos servem, então, para facilitar a produção de sons, ou grupos de sons. Por tratar de unidades tanto da Fonética quanto da Fonologia, esse fenômeno poderia receber dois rótulos: processos fonéticos e processos fonológicos. No entanto, convencionou-se usar apenas a expressão "processos fonológicos".

Os estudos que trazem a ideia de processos fonológicos são amplos e plurais, isto é, falar em processo fonológico é considerar diferentes contextos linguísticos de realização, por exemplo: morfologia, aquisição da linguagem etc. A esse respeito, Stampe (1973, p. 6) afirma: "Although phonological substitution is a mental operation, it is clearly motivated by the physical character of speech - its neuro-physiological, morphological, mechanical, temporal, and acoustic properties"5.

De acordo com Yavas, Hernandorena e Lamprecht (1991, p. 91), considerando uma perspectiva da aquisição da linguagem, os processos fonológicos são inatos, naturais e universais:

[...] os processos são naturais porque derivam das necessidades e dificuldades articulatórias e perceptuais do ser humano; resultam em adaptações dos padrões da fala às restrições naturais da capacidade humana, tanto em termos de produção como de percepção. São inatos porque são limitações com as quais a criança nasce e que ela tem que superar na medida em que não façam parte do sistema de sua lingua materna. Por serem inatos ao ser humano, os processos fonológicos são universais, isto é, encontrados em todas as crianças.

Ainda segundo Yavas, Hernandorena e Lamprecht (1991, p. 92),

[...] os processos fonológicos constituem um instrumento válido e confiável de análise; dão conta da descrição da fonologia em desenvolvimento e da fonologia com desvios; permitem uma comparação clara e simples entre a fonologia com desvios, por um lado, e a aquisição normal e o alvo da fala adulta, por outro; facilitam o estabelecimento de metas racionais de tratamento.

É possivel também considerar processo fonológico a expressão de um fenômeno fonológico em forma de regra. Dito de outra forma, um processo fonológico visa a descrever uma regra relativa a um fenômeno sonoro que ocorre na língua. Por exemplo, em uma perspectiva chomskiana, os processos fonológicos são explicados por meio de regras peculiares à fonologia generativa que articulam a representação fonológica à transcrição fonética.

\section{Metodologia}

A metodologia consiste na busca das características prosódicas de línguas mortas ou de períodos passados de línguas vivas através da estrutura métrico-

4 “[...] um processo fonológico é uma operação mental que se aplica à fala para substituir, no lugar de uma classe de sons ou de uma sequência de sons que apresentam uma dificuldade específica comum para a capacidade de fala do indivíduo, uma classe alternativa idêntica, porém desprovida da propriedade difícil" (tradução nossa).

5 "Apesar de a substituição fonológica ser uma operação mental, ela é claramente motivada pelo caráter físico da fala - suas propriedades neurofisiológicas, morfológicas, mecânicas, temporais e acústicas" (tradução nossa). 
-poética da poesia e foi inaugurada, no Brasil, por Massini-Cagliari (1995). Ademais, baseia-se no mapeamento de processos morfológicos - no caso, as formas verbais do imperativo - e fonológicos - sândi vocálico externo - nas $\mathrm{CSM}^{6}$.

A seguir, como ilustração, apresentamos os exemplos (1) e (2) sobre os procedimentos de mapeamento dos dados de formas verbais do imperativo e de sândi vocálico externo, respectivamente:

(1)

\begin{tabular}{|c|c|}
\hline Códice To & Mettmann (1986, p. 111) \\
\hline 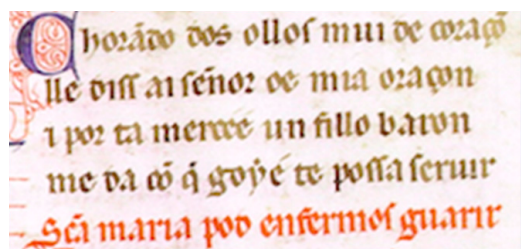 & $\begin{array}{l}\text { Chorando dos ollos mui de coraçôn, } \\
\text { lle diss': "Ai Sennor, oe mia oraçôn, } \\
\text { e por ta mercee un fillo barôn } \\
\text { me dá, con que goi' e te póssa servir." } \\
\text { Santa María pód' enfermos guarir... } \\
\text { (CSM 21, v. 11-14) }\end{array}$ \\
\hline
\end{tabular}

Para a coleta dos dados, analisamos os contextos (função semântica) em que cada forma verbal foi usada em PA e marcamos em negrito, seguido de sublinhado, as ocorrências identificadas, ou seja, o que de fato corresponde às formas verbais imperativas, como pode ser observado no exemplo 1.

No âmbito dos processos fonológicos, marcamos em vermelho os hiatos de palavras terminadas em sílaba aberta; em azul, as elisões; em verde, as ditongações e em amarelo, os hiatos das sequências de ditongos decrescentes.

(2)

\begin{tabular}{|c|c|}
\hline Códice To & Mettmann (1986, p. 93) \\
\hline 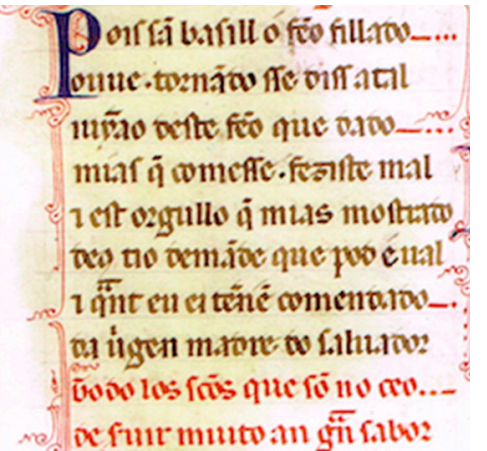 & $\begin{array}{l}\text { Pois San Basill' o fẽo fillado } \\
\text { ouve, tornando-sse diss' atal: } \\
\text { "Juyão, deste fẽo que dado } \\
\text { mi ás que comesse feziste mal; } \\
\text { e est' orgullo que mi ás mostrado, } \\
\text { Deus tio demande, que pod' e val; } \\
\text { e quant' eu ei tenn' encomendado } \\
\text { da Virgen, Madre do Salvador." } \\
\text { Todo-los Santos que son no Ceo | de servir } \\
\text { muito an gran sabor... } \\
\text { (CSM 15, v. 59-67) }\end{array}$ \\
\hline
\end{tabular}

No exemplo (2), trazemos a estrofe 7 , versos 59 a 67. A CSM 15 contém 20 estrofes de nove sílabas poéticas e segue o modelo 9'A9A 9'b9c 9'b9c 9'b9c 9'b9A de rima. Muito embora na estrofe do exemplo não ocorram todos os processos fonológicos, na cantiga é possivel encontrá-los, isto é, na cantiga ocorrem o apa-

6 Contamos, como auxílio na categorização das formas verbais, também com glossários, vocabulários, dicionários e, especialmente, com o glossário de Mettmann (1972). 
gamento de V1 (elisão/crase), a ditongação e a não realização ou o apagamento da V2 (vogal da segunda palavra).

Para o sândi vocálico externo, a escansão e a contagem das sílabas poéticas dos versos são procedimentos pertinentes para elucidação de dúvidas sobre a consideração de uma sequência de vogais pertencentes a duas palavras em uma única ou em sílabas diferentes. A escrita dos manuscritos medievais aqui considerados como fonte, que, por um lado, não é perfeita, pois se trata de uma relação entre fala e escrita, por outro é particularmente reveladora do fenômeno da elisão, já que não costumavam ser grafadas as vogais apagadas nesse processo.

\section{CONSIDERAÇÕES SOBRE OS OBJETOS DE ESTUDO}

\section{Processos morfológicos: modo imperativo}

As gramáticas tradicionais do português ${ }^{7}$ postulam que o imperativo possui formas próprias somente para a segunda pessoa do singular e segunda pessoa do plural. As demais pessoas são extraídas do presente do subjuntivo. O imperativo negativo não apresenta uma formação própria, sendo integralmente suprido pelo presente do subjuntivo, anteposta às formas verbais uma partícula de negação, sendo na maioria das vezes a partícula não.

Cunha (1970, p. 263) afirma que o imperativo afirmativo só possui formas próprias relativas à segunda pessoa, sendo tu para o singular e vós para o plural, derivadas do presente do indicativo. Porém, esse modelo não é aplicado ao português brasileiro (PB) atual falado e escrito. Os autores consideram o pronome "você" como de tratamento de segunda pessoa do discurso, utilizada para as pessoas com quem se fala.

Faraco (1982, p. 205), a respeito dessa mudança no paradigma verbal do PB, afirma que as formas tu e vós estão se tornando obsoletas e "in the terms of Brazil [...] we can say that the normal paradigm of the verbal conjugation in the traditional grammars does not describe the present state of the language"8. O autor ainda constata que, a partir dessa mudança estrutural e da presença das formas homônimas entre as segunda e terceira pessoas do singular, resulta uma mudança sintática que consiste no uso obrigatório do pronome sujeito, o que anteriormente era facultativo.

Câmara Jr. (1975 [1970], p. 136) afirma que no latim o subjuntivo estava associado ao modo imperativo, sendo esse último utilizado para dar ordens e proibições. De acordo com o autor, eram as formas do subjuntivo que supriam as pessoas que faltavam no imperativo: a terceira pessoa (no tratamento do ouvinte nessa pessoa) e a primeira pessoa do plural, quando o falante impõe a outras pessoas uma ordem ou tarefa. Essa estrutura é válida, segundo o autor, para as ordens. Em relação às proibições, caracterizadas pela partícula negativa diante do verbo, em todas as pessoas, as formas subjuntivas são obrigatórias. $\mathrm{O}$ autor, porém, faz uma ressalva dizendo que no latim clássico era utilizada a forma do pretérito perfeito em vez do subjuntivo para o imperativo negativo. $\mathrm{O}$ latim vulgar adotou o emprego do presente (imperfeito), por exemplo: lat. cl. ne feceris, lat. vulg. non facias, port. não faças.

\footnotetext{
Cf. Cegalla (1967), Cunha (1970), Cunha e Cintra (1985), Rocha Lima (1994) e Bechara (2005).

B "em relação ao Brasil, [...] podemos dizer que o paradigma normal da conjugação verbal nas gramáticas tradicionais não descreve o estado atual da língua" (tradução nossa).
} 
Outro aspecto interessante apontado por Câmara Jr. (1975 [1970]) é que desde no latim já existia uma fluidez em relação à concepção do uso do imperativo e do subjuntivo para expressar desejo. Segundo o autor, o uso dele era um modo delicado de dar uma ordem. Isso não ocorria somente no latim vulgar, mas também na linguagem culta coloquial. No Brasil, é profunda a tendência em substituir o imperativo pelo indicativo presente, assim como nas proibições em que também são substituídas as formas do subjuntivo (CÂMARA JR., 1975 [1970], p. 136).

Para Stavrou (1973, p. 93), a forma variante seria o presente do indicativo e esse uso, em vez da forma subjuntiva, ocorre devido a "the softening of command forms", que é uma espécie de suavização das formas imperativas.

Portanto, como pode ser visto, os trabalhos que tratam da mudança sofrida pelas formas verbais imperativas apresentam análises envolvendo dados mais recentes da lingua. Mesmo nas gramáticas históricas, só é possivel notar descrições da estrutura morfológica das formas verbais imperativas e em quais contextos elas eram aplicadas. Em nenhum momento temos uma análise mais detalhada envolvendo dados do estágio inicial da lingua, a fim de averiguar se a situação que encontramos hoje, em relação à dúvida quanto ao imperativo ser um modo independente ou não, já ocorria no PA.

\section{Processos fonológicos: sândi vocálico externo}

O sândi vocálico externo é um processo fonológico que consiste em modificações em contexto de encontros de segmentos vocálicos nas fronteiras de palavras, que modificam ou desfazem a sequência de vogais. Ademais, é um fenômeno da lingua falada, ou seja, oral.

Os sistemas fonológicos selecionam um número finito de segmentos que, combinados, formam as sílabas e que podem ser pronunciados diferentemente dependendo do ambiente em que se encontram, uma vez que as línguas têm processos que afetam os segmentos.

Externamente, o sândi tem de lidar com aspectos de ordem não lexical comuns em todas as linguas - como pausas, hesitações, velocidade de fala - que podem constituir uma barreira para sua aplicação, tornando-o opcional. Nem todas as sequências vocálicas são simplesmente desfeitas por estarem em contato; há outros aspectos específicos presentes em cada língua que bloqueiam a aplicação de sândi externo.

A literatura ${ }^{10}$ sobre o sândi vocálico externo, no PB, traz de forma unânime e sem controvérsias três processos fonológicos que operam em juntura vocálica intervocabular no PB: elisão, degeminação e ditongação. Segundo Bisol (1992), o português é uma língua que revela sensibilidade ao peso da sílaba final, ao choque de acentos e também ao choque de núcleos silábicos em fronteira vocabular. Caso a última sílaba não esteja protegida por acento ou pausa, ocorre a perda de um dos núcleos silábicos e, consequentemente, da sílaba que o domina, operando a ressilabação, que dá origem aos três processos de sândi mencionados.

Bisol (1992) apresenta, em uma perspectiva não linear, duas ideias principais sobre o sândi vocálico externo no PB. A primeira ideia define o sândi externo

\footnotetext{
"abrandamento das formas de comando" (tradução nossa).

10 Ver: Bisol (1989, 1992, 1996, 2000, 2002, 2003), Abaurre (1996), Abaurre, Galves e Scarpa (1999), Tenani (2002, 2003, 2004), Brescancini e Barbosa (2005) e Collischonn (2005 [1996], 2011, 2012).
} 
como um processo de ressilabação que envolve duas palavras sob o domínio do mesmo enunciado, por exemplo:

(3) A casa amarela é bonita (BISOL, 1992, p. 89).

O exemplo (3) corresponde ao de degeminação, processo que ocorre frequentemente no PB quando há vogais iguais adjacentes na sequência de palavras.

A segunda ideia, consequência da primeira, considera que a sílaba resultante - do encontro dessas duas palavras de sequência VV incorporada - pertence à pauta prosódica do vocábulo seguinte. Segundo Bisol (1992), o fenômeno de sândi diz respeito ao desaparecimento de uma sílaba e à imediata ressilabação dos elementos flutuantes, que são agregados à sílaba remanescente, atendendo ao Princípio do Licenciamento Prosódico. Outro princípio que opera no sândi, embora a autora não afirme categoricamente em seu estudo, é o Maximal Syllable Onset Principle [Princípio de Maximização do Ataque], que motiva a incorporação da nova sílaba à pauta prosódica do vocábulo seguinte, maximizando o onset (4):

(4) A ca samarela é bonita (BISOL, 1992, p. 89).

Por fim, os fenômenos são governados pela ressilabação que ocorre automaticamente quando se encontram palavras que formam em suas fronteiras as sequências VV, sendo pronunciadas sem pausa, como parte de uma unidade prosódica maior. Esses processos são favorecidos por duas vogais em sequência que, por ressilabação, ficam sob o domínio da mesma sílaba. Quando ocorre uma ressilabação, os processos de sândi têm em comum o fato de ocorrerem entre dois núcleos silábicos que entraram em contato.

\section{UM OLHAR SOBRE O MAPEAMENTO DOS DADOS}

\section{Processos morfológicos nas CSM}

Após a coleta dos dados, foram analisadas as estruturas morfológicas das formas verbais imperativas encontradas, comparando-as com a estrutura morfológica das formas verbais do presente do indicativo e do subjuntivo presentes no corpus, a fim de explicar se critérios, tais como ordem, presença ou ausência do sujeito e contextos relacionados a atos de fala (ordem ou pedido), podem ser utilizados para considerar uma forma imperativa ou não. O exemplo a seguir representa a divisão morfológica realizada durante a análise dos dados:

(5) Verbo Levar $(\mathrm{PA})=$ Levar $(\mathrm{PB})$

- Imperativo Gramatical: levade

Radical/ Vogal temática/ Sufixo modo-temporal/ Sufixo número-pessoal lev a $\quad \varnothing \quad$-de

- Presente do Indicativo: levades

Radical/ Vogal temática/ Sufixo modo-temporal/ Sufixo número-pessoal lev a $\quad \varnothing \quad$-des

- Presente do Subjuntivo: levedes

Radical/ Vogal temática/ Sufixo modo-temporal/ Sufixo número-pessoal lev

a (e)

$\varnothing$

-des 
A coleta dos dados no corpus proporcionou o mapeamento das formas verbais do modo imperativo nas CSM, para a realização das análises. Apresentaremos nesta seção os resultados obtidos. Foram coletadas 217 formas verbais conjugadas no modo imperativo. Desse total, 175 ocorrências estão conjugadas nas $2^{\mathrm{a}} \mathrm{pp}$ e $2^{\mathrm{a}} \mathrm{ps}$. Optamos por excluir de nossas análises as ocorrências mapeadas na $3^{\mathrm{a}} \mathrm{ps}, 1^{\mathrm{a}} \mathrm{pp}$ e $3 \mathrm{pp}$, pois essas pessoas são todas extraídas do presente do subjuntivo, o que já favorece o uso de uma estrutura morfológica específica e bem demarcada para expressar o modo imperativo.

Entre os itens que podem auxiliar nesta investigação acerca das formas verbais imperativas, destacamos a presença ou a ausência de sujeito nas frases. Todas as ocorrências mapeadas foram analisadas e investigamos o contexto em que as formas verbais estão inseridas. Nas CSM, foram mapeadas três ocorrências com o verbo levar conjugado na segunda pessoa do plural. Veja a seguir as estrofes com os dados:

(6) Pois chegaron, rogou-lles muito chorando dos ollos seus,

dizendo: "Levade-me voc', ay, amigos meus!" (CSM 5, v. 141-142).

[...] e dizian assi: "Varões, levade

e a Santa Maria loores dade" (CSM 134, v. 45-46).

E logo tan toste o meirynno

disse: "Varões, levade-a já

fora da vila cab' o camĩo [...]” (CSM 255, v. 98-100).

Com a divisão sintática dos elementos acima, encontramos a seguinte situação:

(7) Pois chegaron, rogou-lles muito chorando dos ollos seus,

dizendo: "Levade-me voc', ay, amigos meus!" (CSM 5, v. 141-142).

Sujeito: $\varnothing$

Predicado: Levade-me voc', ay, amigos meus

Vocativo: amigos meus

[...] e dizian assi: "Varões, levade

e a Santa Maria loores dade" (CSM 134, v. 45-46).

Sujeito: $\varnothing$

Predicado: levade e a Santa Maria loores dade

Vocativo: Varões

E logo tan toste o meirynno

disse: "Varões, levade-a já

fora da vila cab' o camĩo [...]" (CSM 255, v. 98-100).

Sujeito: $\varnothing$

Predicado: levade-a já fora da vila cab' o camĩo [...]

Vocativo: Varões

Nesses exemplos, o morfema zero representa que o sujeito é nulo. Em relação à posição do sujeito em PA, Mattos e Silva (1993, p. 123) declara que perdidas as marcas flexionais que indicavam o caso ou função sintética dos sintagmas nominais, o português e outras línguas românicas passaram a ter uma ordem sintática mais fixa. Baseada nos trabalhos de Huber (1986) e Pádua (1960), a 
autora afirma que no PA, a ordem sintática mais usada era SVC, ou seja, sujeito, verbo e complemento. Nas CSM, o tipo de ordem mais frequente é VC (verbo-complemento) para as formas verbais conjugadas na $2^{a}$ pp e na $2^{a} \mathrm{ps}$.

\section{Processos fonológicos: sândi vocálico externo nas CSM}

A partir da metodologia apresentada na seção 2, foram mapeados todos os casos de encontros vocálicos intervocabulares, classificando-se cada caso de acordo com o fenômeno de sândi ou hiatos verificados. Todas as soluções adotadas pelo trovador nos ajudaram a evidenciar os limites entre as possibilidades e impossibilidades de processos fonológicos de vogais em juntura vocabular dentro do sistema.

O hiato que surge na frase do PA por combinação de palavras tende a dar lugar, muitas vezes, à elisão, à crase e à ditongação. Passemos às resoluções identificadas nas ocorrências mapeadas e busquemos explicitar, à luz das teorias fonológicas não lineares, a motivação das ocorrências e a representação dos processos.

A ditongação é a ressilabação dos dois segmentos flutuantes que passam a associar-se ao nó silábico subsistente. Perde-se uma sílaba, em função do choque de dois núcleos silábicos em fronteira vocabular, mas todos os segmentos são preservados. Como o contexto da ditongação é a resolução do encontro de vogais em juntura vocabular, temos os seguintes contextos silábicos envolvidos - (8). A resolução em ditongação no PA é minoritária.

(8) a. [CV] [V] - [CVV] (ocorrência majoritária)

b. [CV] [VV] - [CVVV] (somente uma ocorrência)

c. [CV] [VC] [CVVC] (somente uma ocorrência)

A grande maioria dos casos de ditongação acontece entre o pronome mi e a vogal inicial da palavra seguinte (9), em que duas silabas de duas palavras distintas ocorrem em uma mesma sílaba poética:

(9) a. Ca/ tu/ soa/ es/ a/ que/ miol po/des/ dar (CSM 21; verso 45) - verso decassílabo

b. [mi] [o] - [mio]

c. $[\mathrm{CV}][\mathrm{V}]-[\mathrm{CVV}]$

A elisão de encontros vocálicos entre palavras trata-se de uma solução não majoritária, mas estatisticamente relevante. A elisão ocorre quando a vogal da primeira palavra é /a/, /e/ ou /o/ átonos - exemplo em (10):

(10) E os judeus, que sempr' acostumad' an (CSM 27; verso 70)

sempr' acostumad' an = sempre + acostumado + an

[sempre] [acostumado] [an] - [sem] [prascostuma] [dan]

Convém ressaltar que há um caso de apagamento singular, a saber: quando a vogal /a/ átona final da primeira palavra é suprimida. O apagamento ocorre frequentemente quando a vogal inicial da segunda palavra também é /a/:

(11) a. a que vos fezestes atan gran torto, com' agor' aduz (CSM 5; verso 175)

b. [agora] [aduz] $\rightarrow$ [ago] [raduz] 
Massini-Cagliari $(2000,2005)$ havia postulado a diferença de comportamento da queda vocal no PA quando esta é ou não /a/. A autora concluiu estar diante de dois processos diferentes de sândi: 1. quando a vogal da primeira palavra é /a/ e a inicial da palavra seguinte também é /a/, ocorre a crase; 2 . quando a vogal final da primeira palavra é /e/ ou /o/, independentemente da qualidade da vogal seguinte, trata-se de elisão. Nosso estudo corrobora essa distinção, visto que também obtivemos em nosso mapeamento essa discrepância quantitativa da resolução dos encontros vocálicos, quando de um lado /e/ e /o/ são apagados (elisão) e do outro, /a/ (crase, fusão de /a/s).

Por fim, diferentemente das resoluções mostradas acima para o encontro de vogais em juntura intervocabular, é possivel encontrar, no corpus, a não realização ou elisão da vogal inicial da segunda palavra quando é seguida por /s / ou $/ \mathrm{n} /$.

(12) nen/ d' a/gui/llon/ a 's/co/du/das. (CSM 31; verso 68) - 7 sílabas poéticas

(13) e/ di/ss': "Es/ta 'n/fer/me/da/de | se/me/lla/ mui/t' a/fi/ca/da. (CSM 75 ; verso 36) - hemistíquio de 7 sílabas poéticas

Consideramos que, se as propriedades de sonoridade da sílaba estiverem sendo satisfeitas pela junção dos vocábulos em alguns casos, possivelmente, não haverá a necessidade da realização da vogal epentética.

\section{Conclusão}

$\mathrm{Na}$ época dos cancioneiros trovadorescos, a elisão era marcada com a supressão da vogal não realizada, na escrita, e as vogais envolvidas na ditongação ficavam sob o domínio de uma única sílaba poética, logo, uma só sílaba fonética, considerando a nossa metodologia. Essa diferença, se comparada aos padrões de escrita atual, viabiliza este estudo. Dessa forma, levando em consideração as diferenças entre língua falada e língua escrita, no caso da poesia, podemos observar que vários fenômenos que aparecem na escrita das CSM podem elucidar processos fonológicos ocorridos no PA, uma vez que não tínhamos ainda, naquela época, uma ortografia fortemente estabelecida e muitos dos processos de sândi vocálico externo ocorriam não por artifício, opção ou estilo do trovador, mas sim por ser um processo gramatical do PA.

Outrossim, houve, no corpus escolhido para a composição deste estudo, a preferência pelo modo imperativo sem o uso de formas variantes no período medieval. Assim, é possivel constatar, por meio dos resultados obtidos, a exclusividade da forma imperativa em PA, amplamente usada nas interações entre os interlocutores, sobretudo em contextos de ordem ou pedido, situação predominante nas cantigas analisadas. Das ocorrências tanto da $2^{\mathrm{a}}$ ps quanto da $2^{\mathrm{a}} \mathrm{pp}$, todas estavam conjugadas na forma imperativa, uma vez que, ao realizarmos a divisão dos dados em morfemas, notamos que as formas verbais mapeadas no corpus são quase idênticas às formas do presente do indicativo, contudo sem o -s final. Em relação à posição do sujeito em PA, associada às formas verbais imperativas, nas CSM, o tipo de ordem mais frequente é VC (verbo complemento), para as formas verbais conjugadas na $2^{a}$ pp e na $2^{a}$ ps. Esse comportamento sintático já era previsto; por se tratar de formas verbais imperativas, a posição ocupada pelo sujeito é sempre nula. 
Portanto, em nossa opinião, tudo o que foi exposto, desde a primeira página deste artigo, constitui apenas um resumo da importância do estudo de um corpus poético, do português medieval e das CSM. Não é pretensioso dizer que somente quem aprendeu a valorizar, como nós, a Idade Média, essa era da história humana que teve momentos de obscuridade tão proclamados, consegue ver seus momentos de claridade, de intenso brilho, presentes na lingua daquela época.

\section{Morphological and phonological processes in Ancient Portuguese: imperative AND EXTERNAL VOCALIC SANDHI}

Abstract: The main objective of this study is to reflect on the importance of the Cantigas de Santa Maria (CSM) as a corpus for the development of linguistic analyzes related to studies associated with the Portuguese language in the Archaic Portuguese. In relation to morphological and phonological phenomena involving accent and rhythm, it is necessary to consider a corpus that supports them. Thus, poetic texts are pertinent, because there is scansion, which consists of counting the sounds and the verses from the elevation of rhythm or tone of the words.

Keywords: Historical Linguistics. Morphology. Phonology. Archaic Portuguese. Medieval songs.

\section{REFERÊNCIAS}

ABAURRE, M. Acento frasal e os processos fonológicos segmentais. Letras Hoje, Porto Alegre, v. 31, n. 2, p. 41-50, 1996.

ABAURRE, M.; GALVES, C.; SCARPA, E. A interface fonologia-sintaxe: evidências do Português Brasileiro para uma hipótese top-down na aquisição da linguagem. In: SCARPA, E. (org). Estudos da prosódia. Campinas: Editora da Unicamp, 1999. p. 285-323.

BECHARA, E. Moderna gramática portuguesa. 37. ed. Rio de Janeiro: Lucerna, 2005.

BISOL, L. O ditongo na perspectiva da fonologia atual. D.E.L.T.A., São Paulo, v. 5, n. 2, p. 185-224, 1989.

BISOL, L. Sândi vocálico externo: degeminação e elisão. Cadernos de Estudos Linguísticos, Campinas, n. 23, p. 83-101, jul./dez. 1992.

BISOL, L. Constituintes prosódicos. In: BISOL, L. (org.). Introdução a estudos de fonologia do português brasileiro. Porto Alegre: EDIPUCRS, 1996. p. 247-261.

BISOL, L. A elisão, uma regra variável. Letras de Hoje, Porto Alegre, v. 35, n. 1, p. 319-330, 2000.

BISOL, L. Sândi externo: o processo e a variação. In: KATO, M. (org.). Gramática do português falado: convergências. Campinas: Editora da Unicamp, 2002. v. V, p. 53-100.

BISOL, L. Sandhi in Brazilian Portuguese. Probus, v. 15, n. 2, p. 177-200, 2003. BLOOMFIELD, L. Language. Chicago: The University of Chicago Press, 1984 [1933]. 
BRESCANCINI, C.; BARBOSA, C. A elisão da vogal média /e/ no sul do Brasil. Letras de Hoje, Porto Alegre, v. 40, n. 3, p. 39-56, 2005.

CÂMARA JR., J. Estrutura da lingua portuguesa. 15. ed. Rio de Janeiro: Vozes, 1975 [1970].

CEGAllA, D. P. Novíssima gramática da língua portuguesa. 18. ed. São Paulo: Nacional, 1967. p. 94-96.

COLlischONN, G. A sílaba em português. In: BISOL, L. (org.). Introdução a estudos de fonologia do português brasileiro. Porto Alegre: EDIPUCRS, 2005 [1996]. p. 101-134.

COLLISCHONN, G. A interação entre acento e processos de (re)estruturação silábica: um desafio para a Teoria da Otimidade. Revista Linguistica/ Revista do Programa de Pós-Graduação em Linguística da Universidade Federal do Rio de Janeiro, v. 7, n. 1, jun. 2011. Disponivel em: https://revistas.ufrj.br/index. $\mathrm{php} / \mathrm{rl} /$ article/view/4456. Acesso em: jul. 2014.

COLlischonN, G. Sândi Vocálico no Português Brasileiro: como o acento determina sua realização. Letras\&Letras, Uberlândia, v. 28, n. 1, p. 13-27, jan./ jun. 2012.

CUNHA, C. Gramática do português contemporâneo. Belo Horizonte: Bernardo Álvares, 1970.

CUNHA, C.; CINTRA, L. Nova gramática do português contemporâneo. Rio de Janeiro: Nova Fronteira, 1985.

FARACO, C. The imperative sentence in Portuguese: a semantic and historical discussion. 1982. Tese (Doutorado) - University of Salford, Manchester, 1982.

FERREIRA, M. The stemma of the Marian cantigas: philological and musical evidence. Bulletin of the Cantigueiros de Santa Maria. Cincinnati, n. 6, p. 58-98, 1994.

FILGUEIRA VALVERDE, J. Introducción. In: ALFONSO X EL SABIO. Cantigas de Santa Maria: Códice Rico de El Escorial. Madrid: Castalia, 1985. p. XI-LXIII.

HUBER, J. Gramática do português antigo. Lisboa: Fundação Calouste Gulbenkian, 1986 [1933].

LEÃO, Â. V. Questões de linguagem nas Cantigas de Santa Maria, de Afonso X. Ensaios. Associação Internacional de Lusitanistas (AIL). 2002. Disponivel em: http://www.pucrs.br/fale/pos/ail/leao01.htm. Acesso em: 17 jan. 2005.

MASSINI-CAGLIARI, G. Cantigas de amigo: do ritmo poético ao lingüístico. Um estudo do percurso histórico da acentuação em Português. 1995. Tese (Doutorado em Linguística) - Universidade Estadual de Campinas, Campinas, 1995.

MASSINI-CAGLIARI, G. De monossílabos e de elisão. Estudos Linguísticos, São Paulo, Assis, v. 29, p. 345-350, 2000.

MASSINI-CAGLIARI, G. A música da fala dos trovadores. Estudos de prosódia do português arcaico, a partir das cantigas profanas e religiosas. 2005. $348 \mathrm{f}$. Tese (Livre-Docência) - Universidade Estadual Paulista "Júlio de Mesquita Filho", Araraquara, 2005.

MATTOS E SILVA, R. O português arcaico: morfologia e sintaxe. São Paulo: Contexto, 1993. 
MATTOS E SILVA, R. O português arcaico: fonologia, morfologia e sintaxe. São Paulo: Contexto, 2006.

MetTMANN, W. Glossário. In: AFONSO X, O Sábio. Cantigas de Santa Maria. Coimbra: Universidade de Coimbra, 1972. v. IV, Glossário.

MONTEIRO, J. Morfologia portuguesa. Campinas: Pontes, 2002.

O'CALLAGHAN, J. Alfonso $X$ and the cantigas de Santa Maria: a poetic biography. Leiden; Boston; Köln: Brill, 1998.

PÁDUA, M. P. A ordem das palavras no português arcaico. Frases de verbo transitivo. Coimbra: Universidade de Coimbra, 1960.

PARKINSON, S. As cantigas de Santa Maria: estado das cuestións textuais. Anuario de Estudios Literarios Galegos, Vigo, p. 179-205, 1998.

PENA, X. R. Literatura galega medieval. Santiago de Compostela: Gotelo Blanco, 1992.

ROCHA, L. Estruturas morfológicas do português. Belo Horizonte: Editora UFMG, 1999.

ROCHA LIMA, C. Gramática normativa da língua portuguesa. 32. ed. Rio de Janeiro: José Olympio, 1994 [1972].

ROSA, M. Introdução à morfologia. São Paulo: Contexto, 2000.

STAMPE, D. A dissertation on natural phonology. 1973. Tese (Doutorado) - Universidade de Chicago, Chicago, 1973.

STAVROU, C. Portuguese pronouns and command forms. Hispanic, American Association of Teachers of Spanish and Portuguese, p. 92-93, 1973.

TENANI, L. Sândi vocálico e estrutura prosódica. Estudos Linguísticos, São Paulo, p. 1-4, 2002.

TENANI, L. Domínios prosódicos e processos de reestruturação silábica. Estudos Linguísticos, São Paulo, p. 1-4, 2003.

TENANI, L. O efeito de eurritmia e a degeminação. Estudos Linguísticos, São Paulo, n. 33, p. 928-932, 2004.

YAVAS, M.; HERNANDORENA, C. L. M.; LAMPRECHT, R. R. Avaliação fonológica da criança. Porto Alegre: Artes Médicas, 1991. 